American Journal of Agricultural and Biological Sciences 6 (2): 221-226, 2011

ISSN 1557-4989

(C) 2011 Science Publications

\title{
Vitamin B12 Status in Males and Females of different Age Groups
}

\author{
Ala Qatatsheh \\ Department of Nursing, Princess Aisha Bint Al-Hussein \\ Faculty of Nursing, Al-Hussein bin Talal University, Ma'an, Jordan
}

\begin{abstract}
Problem statement: Vitamin B deficiency remains widespread in many countries including Jordan, mainly due to inadequate dietary intake of vitamin B and absorption problems. Approach: Few researches on vitamin B12 status in healthy subjects are carried out. Thus, the aim of this study was to evaluate the serum levels of vitamin B12 in healthy Jordanian subjects living in the city of Ma'an. Randomized samples involving 511 healthy participants aged between 15-80 years whom referred for routine laboratory check up at the medical center of Al-Hussein Bin Talal University (AHU) in Jordan, were subjected to a health screening and then they provided a blood sample. Serum vitamin B12 concentration was determined using the fully automated Abbott AxSYM B12 assay, the accuracy and precision of this method was evaluated using certified reference materials. Results: Prevalence of low vitamin for 15-24-year-old, 25-34-year-old and over 34-year-old age groups among both males 2.7, 2.9 and 5.1\% and females 5.1, 3.9 and 5.8\% respectively were not significantly lower than those were not $\mathrm{B} 12$ deficient $(\mathrm{P}=0.57$ and $\mathrm{P}=0.52$, respectively). The highest prevalence was considered in both male and female over 34-year-old age group which increased by ageing. Conclusion/Recommendations: This study revealed that the prevalence of low vitamin B12 levels are considerably lower than other communities. One possible explanation of these observations is that Jordanians eat adequate animal products to increase the daily intake of vitamin B12. Further studies are needed to confirm these results.
\end{abstract}

Key words: Vitamin B12 deficiency, healthy jordanian, Microparticle Enzyme Intrinsic Factor Assay (MEIA), fully automated Abbott, animal products, DNA synthesis, acidic environment, subjects suffering hematological

\section{INTRODUCTION}

Vitamin B12 also called Cobalamin, is a water soluble vitamin with a key role in the normal function of the brain and nervous system, in DNA synthesis and for the formation of blood (Roddie and Davis, 2009; Solomon, 2007). Vitamin B12 deficiency can lead to a wide spectrum of hematologic and neuropsychiatric disorders that can cause hyperhomocysteinemia and impaired immune system (Ciaffoni, et al., 1992; Pradeep et al., 2009; Pradeep, et al., 2009; Remacha et al., 1991). Symptoms of vitamin B12 deficiency include fatigue, weakness, anorexia, paresthesias, numbness and dizziness. Early diagnosis and prompt treatment of patients in the early stage of the disorder can often produce an improvement in their condition (Erickson et al., 2008; Melinda, 2006; Mohammad et al., 2010).

Vitamin B12 is absorbed from food after binding to the protein intrinsic factor which is produced by the stomach. The acidic environment of the stomach facilitates the release of vitamin B12 that is bound to food. Intrinsic factor, which is released by parietal cells in the stomach, binds to vitamin B12 in the duodenum.
This vitamin B12-intrinsic factor complex is essential for the absorption of vitamin B12 in the terminal ileum (Roddie and Davis, 2009; Schilling, 2004. Since the main sources of vitamin B12 for humans are meat and poultry, as well as dairy products and eggs (Esteve et al., 2002; Flachowsky et al., 2002; Zaman et al., 2009), suggesting that there has been less concern about B12 deficiency among vegetarians those who eat some animal based-products.

Prevalence of vitamin B12 deficiency in the general population appears to increase among elderly people (Wolters et al., 2004). The main causes of vitamin B12 deficiency include nutritional deficiency, malabsorption syndromes, gastrointestinal causes and rare genetic disorders (Roddie and Davis, 2009; Feng et al., 2009; Jang et al., 2002). Absorption problems due to lack of intrinsic or intestinal factors are thought to be the most common cause of vitamin B12 deficiency (Roddie and Davis, 2009).

The distribution of serum concentration of vitamin B12 have been reported in different populations (Baer and Peter, 2011; Vogiatzoglou et al., 2009), but little 
information is available about vitamin B12 concentrations in the healthy Jordanians. Knowledge of vitamin B12 concentrations in the healthy Jordanians would provide a nutritional tool with which to look for nutritional changes and their association with human health. The main objective of this work is to study the distribution of vitamin B12 concentration in a serum sample of healthy Jordanians who live in Ma'an district of Jordan in order to establish whether those subjects have an adequate concentration of vitamin B12.

\section{MATERIALS AND METHODS}

Subject selection: Serum blood samples were taken from 511 healthy participants aged between 15-80 years who were referred for routine laboratory check up at the medical center of AHU in Jordan. All patients with vitamin and mineral supplementation and subjects those with known disorders of vitamins B metabolism, as well as subjects suffering hematological and oncological disorders were excluded. Furthermore, subjects under continuous or recent medication, which are known to influence vitamins B metabolism, women taking hormonal contraception or any other form of hormone substitution, were also excluded.

Ethical consideration: The research was approved by the local ethical committee and was performed according to the Jordanian declaration. All participants gave their written informed consent.

Nutritional habits of the subjects: A dietary history method was used for the evaluation of the dietary habits (Eshaghi et al., 2006; Mamoun et al., 2005). A dietary questionnaire comprising 78 questions was filled in by a specially trained person (dietician, nurse or physician). The questions referred to the daily or weekly consumption of various foodstuffs or groups of foodstuffs. The estimation of the amounts consumed was based on common household measures. The questionnaires were centrally analyzed with a specially constructed computer program at the co-ordinating centre (The medical center of Jordan University, Amaan, Jordan). Information on food composition was given by each participating centre, especially for foods which were local specialties or had a peculiar composition (bulgur, couscous). The results were expressed as daily intake of energy in $\mathrm{kJ}$, while the carbohydrate, protein, fat and total fiber intakes were expressed as g/day contribution to the daily energy intake.
Determination of serum vitamin B12 concentration: Blood samples were centrifuged at $3000 \times \mathrm{g}$ for 5 minutes. The clear serum was stored at $70{ }^{\circ} \mathrm{C}$ until the time of analysis. Serum vitamin B12 concentrations were assessed in one aliquot of stored serum using standard commercial Abbott kits, the AxSYM B12 Assay for the fully automated Abbott AxSYM system (Abbott Diagnostic Division, Longford, Ireland). AxSYM B12 assay is a Microparticle Enzyme Intrinsic Factor Assay (MEIA) for quantitative determination of vitamin B12 in human serum or plasma. The AxSYM $\mathrm{B} 12$ assay is designed to have precision of $\leq 11 \%$ total $\mathrm{CV}$ for concentrations within the B12 low control range and $\leq 10 \%$ total $\mathrm{CV}$ for concentrations in the range of the B12 medium and high controls. The assay was conducted according to the manufacture's instruction using AxSYM analyzer. B12 levels less than 207 $\mathrm{pg} / \mathrm{mL}$ were classified as B12 deficiency.

Statistical analysis: The prevalence of vitamin B12 concentrations according to sex and age group in vitamin B12 deficient subjects and controls were compared using a Chi-square test.

The effect of gender and age groups on the B12 status measurement and the dietary intakes among the subject groups were assessed for statistical significance by ANOVA using SPSS. Data are presented as means \pm SD. Post hoc Tukey's test was performed among the different groups, in order to observe any changes between them. Statistical significance was taken as $\mathrm{P}$ value $<0.05$. All statistical analyses were performed using SPSS version 16.0.

\section{RESULTS}

Subject details and nutritional status: The ages of subjects completing the study was between 18 and 80 with a mean of 34 years. Table 1 summarizes the personal habits and general health of the subjects in this study. Table 2 summarizes the measurement of dietary intakes of macronutrients in those subjects according to different age groups.

The majority of subjects 505 (98.8\%) were nonvegetarians but $6(1.2 \%)$ were vegetarians. Furthermore, $400(78.3 \%)$ and $105(20.6 \%)$ of subjects reported that they had eaten meat and poultry once a week and 2-4 times per week respectively, compared with $6(1.2 \%)$ who reported that they had not eaten any portions of cooked poultry and meat during the past week. 14 subjects $(2.7 \%)$ took vitamin or mineral supplements with antioxidant properties compared with $497(93.7 \%)$ who did not, suggesting that the use of these supplements was less common in subjects in this study compared with those who did not. 
Am. J. Agri. \& Biol. Sci., 6 (2): 221-226, 2011

Table 1: Description of the personal habits and general health of the subjects in the study

\begin{tabular}{lrr}
\hline Personal habits and general health of the subjects: & $(\mathrm{n})$ & $(\%)$ \\
\hline Nutritional status & 6 & 1.2 \\
Vegetarian & 505 & 98.8 \\
Non- vegetarian & 14 & 2.5 \\
Current nutritional supplements & 497 & 97.3 \\
Yes & & 3.9 \\
No & 20 & 96.1 \\
Current medication from GP & 491 & 22.9 \\
Yes & & 18.6 \\
No & 117 & 58.5 \\
General health during the last 12 month & 95 & 299 \\
Worse than average & & 6.3 \\
About the same & 32 & 2.3 \\
Thinking you are suffering from vitamin B12 deficieny & 12 & 91.4 \\
Yes & 467 & \\
No & & \\
\hline
\end{tabular}

Table 2: The daily intakes of macronutrients in the subjects of this study

\begin{tabular}{lcccrc}
\hline & Age1 15-24 year & Age2 25-34 year & Age3 over 34year & & \\
& $\mathrm{n}=185$ & $\mathrm{n}=134$ & $\mathrm{n}=192$ & Pooled SD & P-values \\
\hline Energy $(\mathrm{kJ})$ & 11792.0 & 11772.0 & 10572.0 & 4175.00 & 0.40 \\
Carbohydrate $(\mathrm{g})$ & 327.0 & 314.4 & 294.0 & 116.07 & 0.36 \\
Fat $(\mathrm{g})$ & 111.9 & 124.4 & 99.0 & 55.17 & 0.46 \\
Protein $(\mathrm{g})$ & 100.6 & 102.0 & 93.9 & 34.76 & 0.70 \\
Fiber $(\mathrm{g})$ & 23.9 & 11.5 & 20.5 & 26.93 & 0.28 \\
\hline
\end{tabular}

Table 3: Age and sex of the studied subjects with corresponding vitamin B12 concentrations

\begin{tabular}{|c|c|c|c|c|}
\hline $\operatorname{Sex}^{\mathrm{a}}$ & $\begin{array}{l}\mathrm{Age}^{\mathrm{b}} \\
\text { year }\end{array}$ & $\begin{array}{l}\text { Vitamin } \mathrm{B} 12 \leq 207 \mathrm{pg} \mathrm{mL}^{-1} \\
\text { mean } \pm \text { SD }\end{array}$ & $\begin{array}{l}\text { Vitamin } \mathrm{B} 12 \leq 207 \mathrm{pg} \mathrm{mL}^{-1} \\
\text { mean } \pm \text { SD }\end{array}$ & P-value \\
\hline \multirow{4}{*}{ Male } & $15-24$ & $157.9 \pm 39.75$ & $342.1 \pm 107.17$ & $0.51^{\mathrm{a}}$ \\
\hline & $25-34$ & $135.7 \pm 41.25$ & $363.0 \pm 141.54$ & $0.03^{\mathrm{b}}$ \\
\hline & Over 34 & $152.9 \pm 37.03$ & $465.6 \pm 193.76$ & $0.63^{\mathrm{a}, \mathrm{b}}$ \\
\hline & Total & $149.5 \pm 39.15$ & $397.6 \pm 164.90$ & \\
\hline \multirow{8}{*}{ Female } & $15-24$ & $146.1 \pm 45.00$ & $386.6 \pm 149.90$ & \\
\hline & $25-34$ & $150.8 \pm 39.69$ & $401.0 \pm 181.91$ & \\
\hline & Over 34 & $145.8 \pm 41.36$ & $453.0 \pm 246.23$ & \\
\hline & Total & $147.2 \pm 41.71$ & $412.4 \pm 196.12$ & \\
\hline & $15-24$ & $150.2 \pm 43.10$ & $373.4 \pm 139.74$ & \\
\hline & $25-34$ & $144.3 \pm 40.47$ & $387.6 \pm 168.99$ & \\
\hline & Over 34 & $149.1 \pm 39.22$ & $457.9 \pm 226.56$ & \\
\hline & Total & $148.2 \pm 40.52$ & $407.3 \pm 185.86$ & $340 \pm 197.28(n=511)$ \\
\hline
\end{tabular}

On the other hand, for total energy and the macronutrients carbohydrate, protein, fat as well as fiber there was no significant difference in daily intake between the different age groups, as shown in Table 2.

General health and self-assessment of vitamin B12 deficiency: Use of medication (e.g., Antibiotic, aspirin, paracetamol containing drugs and analgesic drugs) was limited with only 20 subjects using these drugs. 299 $(58.5 \%)$ of subjects felt that their general health had been about the same during the previous 12 months, compared with $95(18.6 \%)$ and 117 (22.9\%) who reported that their health was either worse or better than the average, respectively. $467(91.4 \%)$ of subjects did not know their vitamin B12 status compared with 32 (6.3\%) who believed that they were vitamin B12 deficient and $12(2.3 \%)$ who believed that they were not.

The mean serum concentrations of vitamin B12: The mean serum concentrations of vitamin B12 were compared for both males and females in all age groups between B12 deficient subjects and normal healthy, controls recruited in this study. The results shown in Table 3 show that the mean serum concentrations of vitamin B12 was affected by age, with B12 deficient subjects showing significantly lower B12 concentrations compared with those who had not deficient results $(\mathrm{P}=0.03)$, by increasing age, there was a decreasing in vitamin B12 concentrations, with the exception that the 25-34-year-old in both males and females had a different pattern compared with the different age groups. 
Am. J. Agri. \& Biol. Sci., 6 (2): 221-226, 2011

Table 4: Prevalence of low and normal vitamin B12 concentrations according to sex and age group

\begin{tabular}{|c|c|c|c|c|c|}
\hline $\operatorname{Sex}^{\mathrm{a}}$ & $\begin{array}{l}\mathrm{Age}^{\mathrm{b}} \\
\text { year }\end{array}$ & $\begin{array}{l}\text { Vitamin } \mathrm{B} 12 \leq 207 \mathrm{pg} \mathrm{mL}^{-1} \\
\mathrm{n}(\%)\end{array}$ & $\begin{array}{l}\text { Vitamin } \mathrm{B} 12>207 \mathrm{pg} \mathrm{mL}^{-1} \\
\mathrm{n}(\%)\end{array}$ & $\begin{array}{l}\text { Total } \\
\mathrm{n}(\%)\end{array}$ & P-value \\
\hline \multirow[t]{4}{*}{$\mathrm{Male}^{\mathrm{al}}$} & $15-24$ & $14(2.7)$ & $43(8.4)$ & $57(11.5)$ & $0.12^{\mathrm{a}}$ \\
\hline & $25-34$ & $15(2.9)$ & $35(6.8)$ & $50(9.7)$ & $1.52^{\mathrm{b}}$ \\
\hline & Over 34 & $26(5.1)$ & $53(10.3)$ & $79(15.4)$ & $0.57^{\mathrm{a} 1 \mathrm{~b}}$ \\
\hline & total & $55(10.8)$ & $131(25.6)$ & $186(36.4)$ & $0.52^{\mathrm{a} 2 . \mathrm{b}}$ \\
\hline \multirow[t]{8}{*}{ Female $^{\mathrm{a} 2}$} & $15-24$ & $26(5.1)$ & $102(19.9)$ & $128(25.0)$ & \\
\hline & $25-34$ & 20(3.9) & $64(12.5)$ & $84(16.4)$ & \\
\hline & Over 34 & $30(5.8)$ & $83(16.2)$ & $113(22.1)$ & \\
\hline & total & $76(14.8)$ & $249(48.7)$ & $325(63.6)$ & \\
\hline & $15-24$ & $40(7.8)$ & $145(28.3)$ & $185(36.2)$ & \\
\hline & $25-34$ & $35(6.8)$ & $99(19.4)$ & $134(26.2)$ & \\
\hline & Over 34 & $56(11.0)$ & $136(26.6)$ & $192(37.6)$ & \\
\hline & total & $131(25.6)$ & $380(74.3)$ & 511 & \\
\hline
\end{tabular}

However, mean serum concentrations of vitamin B12 in both males $(149.5 \mathrm{pg} / \mathrm{mL})$ and females $(147.2$ $\mathrm{pg} / \mathrm{mL}$ ) were not significantly lower in those who had deficient results compared with those who had not $(\mathrm{P}=0.51)$. These results suggest that there was no significant effect of gender on the data, although values for females appeared to be lower than for males in B12 deficient subjects, the reverse was true for control subjects. In addition the lowest concentration of vitamin B12 was determined in male 25-34- year-old age groups and in female over 34-year-old age groups as shown in Table 3. The mean serum concentrations of low vitamin for 15-24-year-old, 25-34-year-old and over 34-year-old age groups among both males and females were 157.9, 135.7, $152.9 \mathrm{pg} / \mathrm{mL}$ and 146.1, 150.8, $145.8 \mathrm{pg} / \mathrm{mL}$ respectively were not significantly lower than those were not $\mathrm{B} 12$ deficient $(\mathrm{P}=0.63)$. These results suggest that there was no significant difference between these factors for the interaction between gender and age groups.

The true prevalence of vitamin B12 deficiency: Average age of the group studied was 34 years (range 15-80). There were $186(36.4 \%)$ males and 325 (63.3\%) females. $74.3 \%(n=380)$ of participants had normal vitamin B12 concentrations (>207 pg/mL), but low vitamin B12 levels $(\leq 207 \mathrm{pg} / \mathrm{mL})$ were detected in $25.6 \%(n=131)$. About $37.5 \%(192 / 511)$ of the study population was older than 34 years; $29.1 \%$ (56/192) of this group were B12 deficient. Risk of deficiency appeared to be similar for people for 15-24-year-old and 25-34-year-old age groups (7.8 and $6.8 \%$ respectively), which were not significantly lower than those who were not $\mathrm{B} 12$ deficient $(\mathrm{P}=1.52)$. Prevalence of vitamin B12 concentrations according to sex and age group are shown in Table 4.

\section{DISCUSSION}

The present study showed that $10.8 \%(n=55)$ of males and $14.8 \%(n=76)$ of females were B12 deficient which was not significantly lower than those who were not B12 deficient in both males $(25.6 \%, \mathrm{n}=131)$ and females $(48.7 \%, n=249)$ respectively $(P$ value $=0.12)$. Prevalence of low vitamin for 15-24-year, 25-34-year and over 34-year-old age groups among both males 2.7 , 2.9 and $5.1 \%$ and females $5.1,3.9$ and $5.8 \%$ respectively were not significantly lower than those who were not $\mathrm{B} 12$ deficient $(\mathrm{P}=0.57$ and $\mathrm{P}=0.52$ respectively). The highest prevalence was considered in both male and female over 34-year-old age group. Based on results of the present study, the prevalence of low vitamin B12 levels were higher in females than in males and risk of deficiency was higher among over 34 year-old age groups for both males and females, which, was younger than populations in some previous studies (Papandreou et al., 2006; Roehl et al., 2008).

The values of total vitamin B12 concentration for population $(340 \pm 197.2, \mathrm{n}=511)$ is notably higher than what other surveys reported (Bindra et al., 1987; Vogiatzoglou et al., 2009). In addition, the present study observed that the prevalence of low vitamin B12 concentration was $25.6 \%$. Probably low prevalence of low vitamin B12 concentration in this sample caused an increase in the mean of B12 concentration. In other words, although the mean B12 concentration is high, the severity of deficiency is not that much. Further more, B12 concentrations compared to values from various countries, indicate that the prevalence of low vitamin B12 concentrations were lower than other populations (Bindra et al., 1987; Vogiatzoglou et al., 2009). These results suggest that Jordanians eat adequate animal products to increase the daily intake of vitamin B12. However, it is possible that there may be other important factors like geographical variation (Bindra et al., 1987), different life style (Papandreou et al., 2006), racial and ethnic differences (Bindra et al., 1987), genetic factors (Feng et al., 2009; Jang et al., 2002), normal absorption of vitamin B12 (Roddie and Davis, 2009), the storage period of fresh juices (Chandrasekaram et al., 2009), adequate daily intake of vitamin B12 and folic acid (Fenech, 2001), the plasma level of vitamin $\mathrm{E}$ and vitamin $\mathrm{C}$ (Adewolu and Aro, 
2009; Madhavi et al., 2009) as well as the accurate cooking of vegetables (Rowe et al., 2009) and folic acid supplementation of grain products (Roddie and Davis, 2009), that were not taken in consideration in this study that could influence the vitamin B12 status of subjects.

Finally, in order to relate our findings to the human diet in the future it will be important to assess vitamin B12 content in different food species consumed in Jordan. It would also be interesting to evaluate the vitamin B12 content of complete meals, hospital diet, as well as food from animal sources since there is no information available concerning these items. Since it is emerging that genetic factors influence vitamin B12 metabolism (Feng et al., 2009; Jang et al., 2002), it would be useful to complement such studies with an analysis of relevant genetic polymorphisms. Furthermore, it would be interesting to establish whether genetic variations in candidate genes in combination with nutritional factors (e.g., vitamin B12 status) are associated with susceptibility to common disease.

The present study has some important limitations. First, this study based on serum B12 results, which alone, without biochemical markers such as methylmalonic acid or homocysteine, that might be associated to elevated vitamin B12 concentrations. Second, dietary information was not consistently available. Third, the smaller sample size of male's participants in comparison to females. This limitation caused our inability to precisely evaluate the prevalence of low vitamin B12 in young males.

\section{CONCLUSION}

These results revealed that the prevalence of low vitamin B12 concentrations is considerably lower than in other communities. One possible explanation of these observations is that Jordanians eat adequate animal products to increase the daily intake of vitamin B12. Further investigation is needed to confirm these results.

\section{ACKNOWLEDGEMENT}

This study was supported by a grant fund from the Scientific Research Deanship of Al- Hussein Bin Talal University, Jordan. The authors kindly thank Mr. Ali Osofi, Al- Hussein Bin Talal University, Jordan, for collecting blood samples.

\section{REFERENCES}

Adewolu, M.A. and O.O. Aro, 2009. Growth, feed utilization and haematology of carias gariepinus (Burchell, 1822) gingerlings fed diets containing different levels of vitamin C. Am. J. Applied Sci., 6: $\quad 1675-1681 . \quad$ DOI: 10.3844/ajassp.2009.1675.1681
Baer, J. and M.S. Peter, 2011. Vitamin B12 assessment and intervention in younger adult women. J. Nurse Practitioners, 7: 117-122. DOI: 10.1016/J.NURPRA.2010.08.020

Bindra, G.S., R.S. Gibson and M. Berry, 1987. Vitamin B12 and folate status of East Indian immigrants living in Canada. Nutrition Res., 7: 365-374. DOI: 10.1016/S0271-5317(87)80129-X

Chandrasekaram, K., M.H. Ng, Y.M. Choo and C.H. Chuah, 2009. Effect of storage temperature on the stability of phytonutrients in palm concentrates. Am. J. Applied Sci., 6: 529-533. DOI: 10.3844/ajassp.2009.529.533

Ciaffoni, S., R. Luzzati, C. Roata, A. Turrini, O. Antonello and G. Aprili, 1992. Presence and significance of cold agglutinins in patients with HIV infection. Haematologica., 77: 233-236. PMID: 1427429

Erickson, KI., B.L. Suever, R.S. Prakash, S.J. Colcombe and E. McAuley et al., 2008. Greater intake of vitamins B6 and B12 spares gray matter in healthy elderly: A voxel-based morphometry study. Brain Res., 1199: 20-26. PMID: 18281020

Eshaghi, S.R., M.A. Ramezani, A, Shahsanaee and A, Pooya, 2006. Validity and reliability of the short form-36 items questionnaire as a measure of quality of life in elderly Iranian population. Am. J. Applied Sci., 3: 1763-1766. DOI: 10.3844/ajassp.2006.1763.1766

Esteve, M.J., R. Farré, A. Frigola and C. Pilamunga, 2002. Contents of vitamins B1, B2, B6 and B12 in pork and meat products. Meat Sci., 62: 73-78. DOI: 10.1016/S0309-1740(01)00230-3

Fenech, M., 2001. The role of folic acid and Vitamin B12 in genomic stability of human cells. Mutat. Res., 475: 57-67. PMID: 11295154

Feng, L., J. Li, K.B. Yap, E.H. Kua and T.P. Ng, 2009. Vitamin B-12, apolipoprotein E genotype and cognitive performance in community-living older adults: Evidence of a gene-micronutrient interaction. Am. J. Clin. Nutr., 89: 1263-1268. PMID: 19244370

Flachowsky, G., D. Engelman, A. Sünder, I. Halle and H.P Sallmann, 2002. Eggs and poultry meat as tocopherol sources in dependence on tocopherol supplementation of poultry diets. Food Res. Int., 35: 239-243. DOI: 10.1016/S0963-9969(01)00191-0

Jang, Y., H.Y. Park, J.H. Lee, H.J. Ryu and J.Y. Kim et al., 2002. A polymorphism of the methylenetetrahydrofolate reductase and methionine synthase gene in CAD patients: association with plasma folate, vitamin B12 and homocysteine. Nutr. Res., 22: 965-976. DOI: 10.1016/S0271-5317(02)00416-5 
Madhavi, M.S., P. Kumar and A. HemanthVictor Lalitha, 2009. Effect of antioxidant vitamins $\mathrm{C}$ and E supplementation on its plasma levels and on Lipid profile in pulmonary tuberculosis patients 26. Am. J. Infect. Dis., 5: 263-272. DOI: 10.3844/ajidsp.2009.263.272

Mamoun, N., S. Homedia, M. Mabyou and H.M. Ahmed Muntasir, 2005. Prevalence, types and rsk factors for malnutrition in displaced Sudanese children. Am. J. Infect. Dis., 1: 84-86. DOI: 10.3844/ajidsp.2005.84.86

Melinda, M., 2006. Homocysteine, B vitamins and heart disease. supplementschat.

Mohammad, F.I., S. Awawdeh, A, Saleh and N.A. Bashir, 2010. Total level of serum homocysteine in males and females with coronary heart disease of Different Age Groups. Am. J. Biochem. Biotechnol., 6: 116-119. http://www.scipub.org/fulltext/ajbb/ajbb62116119.pdf

Papandreou, D., I. Mavromichalis, A. Makedou, I. Rousso and M. Arvanitidou, 2006. Total serum homocysteine, folate and vitamin B12 in a Greek school age population. Clin. Nutr., 25: 797-802. PMID: 16690175

Pradeep, M.A., M. Thiruvalluvan and V. Dhamodharan, 2009. A study on erythrocytic determination of anemic condition among human immunodeficiency virus sero positives. Am. Med. J., 1: 80-83. DOI: 10.3844/amjsp.2009.80.83

Pradeep, M.A., M. Thiruvalluvan, K. Aarthy and J.M. Mary, 2009. Determination of iron deficiency among human immunodeficiency virus sero positives. Am. Med. J., 1: 77-79. DOI: 10.3844/amjsp.2009.77.79

Remacha, A.F., A. Riera, J. Cadafalch and E. Gimferrer, 1991. Vitamin B-12 abnormalities in HIV-infected patients. Eur. J. Haematol., 47: 60-64. PMID: 1868915
Roddie, C. and B. Davis, 2009. Iron, B12 and folate. Medicine, $\quad 37$ : 125-128. DOI: 10.1016/j.mpmed.2008.12.009

Roehl, K., C.C. Tangney and M.J. Kwasny, 2008. Prevalence of inadequate vitamin B12 status in the absence of macrocytic anemia among adults aged 45 years or older. J. Am. Dietetic Association, 108: 24-24.

Rowe, J.P., L.V. Ogden, O.A. Pike, F.M. Steele and M.L. Dunn, 2009. Effect of end-user preparation methods on vitamin content of fortified humanitarian food-aid commodities. J. Food Composition Anal., 22: 33-37. DOI: 10.1016/J.JFCA.2008.09.004

Schilling, R.F., 2004. Intrinsic factor studies: II. The effect of gastric juice on the urinary excretion of radioactivity after the oral administration of radioactive vitamin B12. J. Lab. Clin. Med., 144: 268-272. PMID: 15570245

Solomon, L.R., 2007. Disorders of cobalamin (Vitamin B12) metabolism: Emerging concepts in pathophysiology, diagnosis and treatment. Blood Rev., 21: 113-130. PMID: 16814909

Vogiatzoglou, A., A.D. Smith, E. Nurk, P. Berstad and C.A. Drevon et al, 2009. Dietary sources of vitamin B-12 and their association with plasma vitamin B-12 concentrations in the general population: The hordaland homocysteine study. Am. J. Clin. Nutr., 89: 1078-1087. http://www.ajcn.org/content/89/4/1078.short

Wolters, M., A. Strhle and A. Hahn, 2004. Cobalamin: A critical vitamin in the elderly. Prev. Med., 39: 1256-1266. PMID: 15539065

Zaman, M.Z., A.S. Abdulamir, F.A. Bakar, J. Selamat and J. Bakar, 2009. A review: Microbiological, physicochemical and health impact of high level of biogenic amines in fish sauce. Am. J. Applied Sci., 6: 1199-1211. DOI: 10.3844/ajassp.2009.1199.1211 